\title{
Involvement of calmodulin in regulation of primary root elongation by $N$-3-oxo-hexanoyl homoserine lactone in Arabidopsis thaliana
}

\author{
Qian Zhao ${ }^{1,2+}$, Chao Zhang ${ }^{1+}$, Zhenhua Jia ${ }^{1,2}$, Yali Huang ${ }^{1,2}$, Haili Li $^{1}$ and Shuishan Song ${ }^{1,2 *}$ \\ Department of Bioengineering, Biology Institute, Hebei Academy of Sciences, Shijiazhuang, China \\ ${ }^{2}$ Hebei Engineering and Technology Center of Microbiological Control on Main Crop Disease, Shijiazhuang, China
}

Edited by:

Adam Schikora, Justus-LiebigUniversität Giessen, Germany

\section{Reviewed by:}

José López-Bucio, Universidad Michoacana de San Nicolás de Hidalgo, Mexico

Anton Hartmann, German Research Center for Environmental Health,

Germany

\section{*Correspondence:}

Shuishan Song, Department of

Bioengineering, Biology Institute, Hebei Academy of Sciences, 46th, South Street of Friendship,

Shijiazhuang, Hebei 050051, China e-mail: shuishans620@163.com

these authors have contributed equally to this work.
Many bacteria use signal molecules of low molecular weight to monitor their local population density and to coordinate their collective behavior in a process called "quorum sensing" (OS). N-acyl-homoserine lactones (AHLs) are the primary QS signals among Gram-negative bacteria. AHL-mediated OS plays an essential role in diverse bacterial physiological processes. Recent evidence shows that plants are able to sense bacterial AHLs and respond to them appropriately. However, little is known about the mechanism by which plants perceive and transduce the bacterial AHLs within cells. In this study, we found that the stimulatory effect of N-3-oxo-hexanoyl homoserine lactone (3OC6-HSL) on primary root elongation of Arabidopsis was abolished by the calmodulin (CaM) antagonists N-(6-aminohexyl)-5-chloro-1-naphthalene sulfonamide (W-7) and trifluoperazine (TFP). Western-blot and ELISA analysis revealed that the concentration of CaM protein in Arabidopsis roots increased after treatment with $1 \mu \mathrm{M} 30 \mathrm{OC}-\mathrm{HSL}$. Results from quantitative RT-PCR demonstrated that the transcription of all nine CaM genes in Arabidopsis genome was up-regulated in the plants treated with 30C6-HSL. The loss-of-function mutants of each AtCaM gene (AtCaM1-9) were insensitive to 30C6-HSL-stimulation of primary root elongation. On the other hand, the genetic evidence showed that $\mathrm{CaM}$ may not participates the inhibition of primary root length caused by application of long-chained AHLs such as C10-HSL and C12-HSL. Nevertheless, our results suggest that $\mathrm{CaM}$ is involved in the bacterial 30C6-HSL signaling in plant cells. These data offer new insight into the mechanism of plant response to bacterial QS signals.

Keywords: quorum sensing, calmodulin, $\mathbf{N}$-acyl-homoserine lactone, signal transduction, plant development

\section{INTRODUCTION}

Bacteria sense their population density and act in concert using signal molecules of low molecular weight in a process termed "quorum-sensing" (QS) (Bassler, 1999; Fuqua et al., 2001; Taga and Bassler, 2003). These signal molecules, also called autoinducers, are often $N$-acyl homoserine lactones (AHLs) in gramnegative bacteria (Fuqua and Greenberg, 2002). Bacterial QS plays a central role in a variety of bacterial behaviors including biofilm production, induction of bioluminescence, antibiotic production and virulence factor expression (Miller and Bassler, 2001; Quiñones et al., 2005). In recent years, evidence has accumulated that plants are able to detect bacterial QS signal molecules and respond to these signals with altered gene expression or modification in development. The first evidence for the promoting effects of AHLs on plant root growth is reported by von Rad et al. (2008). They found that inoculation of Arabidopsis roots with $\mathrm{N}$-hexanoyl homoserine lactone (C6-HSL) led to increased root elongation (von Rad et al., 2008). Thereafter, a growing body of evidence showed that AHLs can regulate primary root growth in a dose- and structure-dependent manner. The short-chained AHLs such as $N$-butyryl homoserine lactone (C4-HSL), $N$-hexanoyl homoserine lactone (C6-HSL), $\mathrm{N}$-3-oxo-hexanoyl homoserine lactone (3OC6-HSL) and $\mathrm{N}$-3oxo-octanoyl homoserine lactone (3OC8-HSL) within concentration of $1-10 \mu \mathrm{M}$ promote root growth of Arabidopsis (von Rad et al., 2008; Jin et al., 2012; Liu et al., 2012). However, AHLs with longer side-chains influence root growth in a manner different from short-chain AHLs. $\mathrm{N}$-3-oxo-decanoyl homoserine lactone (3OC10-HSL) can induce the formation of adventitious roots in mung beans (Bai et al., 2012). C10-HSL and 3OC12HSL are found to have strong activity in inhibiting root growth and stimulating lateral root and root hair development when more than $50 \mu \mathrm{M}$ AHLs are applicated (Ortiz-Castro et al., 2008, 2011). Furthermore, accumulating evidence indicated that watersoluble short-chain AHLs are actively taken up into plant roots and transported along the roots into the shoot; in contrast, the lipophilic long-chain AHLs can't be transported in barley and Arabidopsis (Götz et al., 2007; von Rad et al., 2008; Sieper et al., 2014). More recently, Palmer et al. reported that the root growth effects of AHLs with long aliphatic acyl groups are dependent upon AHL amidolysis by a plant-derived fatty acid amide hydrolase (FAAH) to yield L-homoserine (Palmer et al., 2014). 
On the other hand, some AHLs or AHL-producing bacteria induced resistance against microbial pathogens (Schuhegger et al., 2006; Schikora et al., 2011; Schenk et al., 2012, 2014; Zarkani et al., 2013). 3OC14-HSL has been shown to induce resistance against biotrophic and hemibiotrophic pathogens in Arabidopsis and barley (Schikora et al., 2011). Similarly, resistance against Pseudomonas syringae induced by Sinorhizobium meliloti in Arabidopsis plants depended on the accumulation of AHL (Zarkani et al., 2013). Transcriptomic and proteomic analysis showed that treatments of plant with bacterial AHLs elicit significant changes in gene transcription and protein expression (Mathesius et al., 2003; Ortiz-Castro et al., 2008; Miao et al., 2012; Schenk et al., 2014). Arabidopsis mutants like $d r r 1$ and $d h m 1$ that are tolerant or hypersensitive to alkamides from plants show alterations in primary and lateral root development and in root responses to $\mathrm{C} 10-\mathrm{HSL}$, indicating that medium-chained AHLs and alkamides act through common signaling mechanisms (Morquecho-Contreras et al., 2010; Pelagio-Flores et al., 2013). All these data indicated that AHLs might mediate the interaction between bacteria and their host plant (Hartmann et al., 2014). However, the signal transduction pathways of AHLs in plant cells are widely unexplored so far. The identification and investigation of those components in signaling will be crucial to understand the mechanism of plant response to bacterial AHLs.

Calcium is an ubiquitous second messenger in plants. Intracellular cytosolic free $\mathrm{Ca}^{2+}$ concentration $\left(\left[\mathrm{Ca}^{2+}\right]_{i}\right)$ often shows significant elevation in response of plant to various environmental stimuli (Knight et al., 1991; van der Luit et al., 1999). $\mathrm{Ca}^{2+}$ signals are sensed and translated into proper cellular response by diverse $\mathrm{Ca}^{2+}$ binding proteins and their downstream targets. Calmodulin (CaM) is an acidic $\mathrm{Ca}^{2+}$ binding protein that possesses EF hand motifs, a helix-loop-helix structure for binding one $\mathrm{Ca}^{2+}$ ion. Upon $\mathrm{Ca}^{2+}$ binding, CaM undergoes conformational changes that promote either its own catalytic activity or its interaction with target proteins (Chin and Means, 2000; Snedden and Fromm, 2001; Cheval et al., 2013). $\mathrm{Ca}^{2+}$ -CaM signaling has been implicated in various developmental and adaptation responses. Many exogenous and endogenous factors including light, temperature, drought and salt stress, pathogen-derived molecules and phytohormones provoke elevation in $\left[\mathrm{Ca}^{2+}\right]_{i}$ of plants (Sander et al., 1999). Likely, the level of CaM was up-regulated by heat-shock (HS) in maize seedlings (Gong et al., 1997). Pharmocological analysis revealed that CaM participated in signal transduction in lemon in response to bacterial pathogen Alternaria alternata (Ortega et al., 2002). Studies of plants demonstrated the presence of multiple CaM gens that encode numerous CaM isoforms (Lee et al., 1995; Takezawa et al., 1995; Yang et al., 1996; Snedden and Fromm, 2001; Yamakawa et al., 2001; Zielinski, 2002). Braam and Davis (1990) reported that the expression of many plant $\mathrm{CaM}$ genes are induced by rain, wind and touch. Among of eight CaM genes in potato plants, PCM1 showed an increase in expression upon touching and PCM6 during tuberization (Takezawa et al., 1995). Soybean CaM genes $S C a M-4$ and $S C a M-5$ are reported to be required for defense against pathogen attack (Heo et al., 1999). AtCaM3, one of nine Arabidopsis CaM genes, has been shown to be involved in $\mathrm{Ca}^{2+}$-CaM mediated HS signal transduction pathway
(Liu et al., 2003, 2005; Zhang et al., 2009). Recently, we have reported evidence for a transient elevation in $\left[\mathrm{Ca}^{2+}\right]_{i}$ upon the exposure of Arabidopsis roots to C4-HSL (Song et al., 2011). Given that $\mathrm{CaM}$, as a $\mathrm{Ca}^{2+}$ sensing protein, translates $\mathrm{Ca}^{2+}$ to downstream protein targets in numerous signal transduction cascades, CaM might be involved in bacterial AHL signaling in plant cells. However, there is no direct evidence for the participation of CaM in AHL-mediated primary root elongation in plants.

In this paper, we first demonstrated the involvement of $\mathrm{CaM}$ in 3OC6-HSL mediated primary root growth in Arabidopsis using pharmacological approaches. Then we observed the increased level of CaM protein and $\mathrm{CaM}$ gene transcription after treatment with 3OC6-HSL. Furthermore, we used T-DNA knockout mutants to provide genetic evidence for the role of individual CaM gene in primary root elongation regulated by 3OC6-HSL. A possible regulatory model of $\mathrm{Ca}^{2+}$-CaM in AHL signaling in plant cells is discussed.

\section{MATERIALS AND METHODS PLANT MATERIALS AND GROWTH CONDITIONS}

Arabidopsis thaliana (L.) cv. Columbia-0, the T-DNA insertion null mutants cam1 (CS872565), cam5 (SALK_007371C), cam6 (SALK_071609C), cam7 (SALK_074336C), cam8 (SALK_022524C) and cam9 (SALK_040392) purchased from ABRC (http://abrc.osu.edu), and cam2, cam3, and cam4 generously gifted from Prof. Sujuan Cui in Hebei Normal University were used in this study. All seeds were surface-sterilized by $75 \%$ $(\mathrm{v} / \mathrm{v})$ ethanol for $30 \mathrm{~s}$ and $20 \%(\mathrm{v} / \mathrm{v}) \mathrm{NaClO}$ for $5 \mathrm{~min}$. After five washes with sterile distilled water, seeds were geminated on agar plates containing Murashige and Skoog (MS) medium (Murashige and Skoog, 1962) adjusted to $\mathrm{pH}$ 5.8. The plates were stratified at $4^{\circ} \mathrm{C}$ for 2 days and then placed in a plant growth chamber with a photoperiod of $12 \mathrm{~h}$ of light, $12 \mathrm{~h}$ of darkness, light intensity of $100 \mu \mathrm{mol} \cdot \mathrm{m}^{2} \cdot \mathrm{s}^{-1}$ and temperature of $22 \pm 2^{\circ} \mathrm{C}$. For primary root growth assay, the seeds were grown vertically for 3 days on MS agar plates, and the seedlings with similar root length were transferred to $1 / 2 \mathrm{MS}$ agar plates containing the indicated compounds. For qRT-PCR assay, a hydroponic system was employed to cultivate Arabidopsis. Seedlings germinated on MS agar plates for 10 days were transplanted into a sterile plastic basin $(18$ by $11 \mathrm{~cm}$ ) containing $500 \mathrm{ml}$ of sterile Hoagland medium. After 7 days, the seedlings were used for compounds treatments. Plants grown under these conditions were more vigorous than those grown in potting media, uniformly absorbing solution with AHL. To ensure that the hydroponic system is free of bacterial contamination, the medium and compound solution were sterilized by passing them through a $0.22-\mu \mathrm{m}$ filter just prior to use. The untreated plants were taken as the control. After harvest, an aliquot of the growth medium was plated on bacterial growth medium and incubated overnight to check for contaminations that occurred during the experiment. Any contaminated samples were discarded. For mutants identification assay, seedlings germinated on MS agar plates for 10 days were transplanted into vermiculite media and watered Hoagland medium once a week. After 1 month, the leaves of seedlings were harvested for RT-PCR. 


\section{COMPOUNDS}

$N$-( $\beta$-ketocaproyl)-DL-homoserine lactone (3OC6-HSL), $\mathrm{N}$-decanoyl-DL-homoserine lactone (C10-HSL) and $\mathrm{N}$ dodecanoyl-DL-homoserine lactone (C12-HSL) were purchased from Sigma-Aldrich (Taufkirchen, Germany), stored dry and diluted as $10 \mathrm{mM}$ stock solutions in $\mathrm{dH}_{2} \mathrm{O}$ or ethanol just prior to use. Trifluoperazine (TFP) was purchased from Sigma (USA) and diluted as $10 \mathrm{mM}$ stock solutions in methanol. $N$-(6-aminohexyl)-5-chloro-1-naphthalene-sulfonamide (W-7) was purchased from Santa Cruz Biotechnology (USA) and diluted as $10 \mathrm{mM}$ stock solutions in $\mathrm{dH}_{2} \mathrm{O}$. $\mathrm{N}$-(6-aminohexyl)1-naphthalene-sulfonamide hydrochloride ( $\mathrm{W}-5)$ was purchased from Tokyo Chemical Industry (TCI, Japan) and diluted as $10 \mathrm{mM}$ stock solutions in $\mathrm{dH}_{2} \mathrm{O}$. All compound solutions were sterilized by passing them through a $0.22-\mu \mathrm{m}$ filter.

\section{PHARMACOLOGICAL ASSAY}

CaM antagonists TFP, W-7 and W-5 were used for pharmacological assay. W-5 is the dechlorinatd analog of W-7 and is often used as control compound for understanding the specificity of $\mathrm{W}-7$. After germination for 3 days, Arabidopsis (Columbia, Col0 ) seedlings with similar root length were transferred to $1 / 2 \mathrm{MS}$ medium plates containing the indicated concentrations of 3OC6HSL or/and CaM antagonists. The untreated plants were taken as the control. Seedlings were grown vertically with the same growth condition as described above, and primary root length was assessed with a ruler after 7 days. The concentration of TFP used in this study ranged from 1 to $50 \mu \mathrm{M}$, while the concentration of W-7 and W-5 ranged from 30 to $200 \mu \mathrm{M} .1 \mu \mathrm{M}$ 3OC6-HSL was used in all experiments. The results were normalized to the root length of control samples. Four to six independent experiments were done and data shown are the average of 30 samples.

\section{IMMUNODETECTION OF CaM}

Seventeen-day-old Arabidopsis Col-0 (Columbia, Col-0) seedlings by hydroponic culture were treated with $1 \mu \mathrm{M}$ 3OC6HSL. The untreated plants were taken as the control. Roots were harvested at $0,1,2,3,6,12$, and $24 \mathrm{~h}$ after 3OC6-HSL treatment and powdered with liquid nitrogen. Total protein were extracted with protein extracting buffer [50 mM Tris- $\mathrm{HCl}(\mathrm{pH} 7.5), 5 \mathrm{mM}$ EDTA, 5 mM EGTA, $10 \mathrm{mM}$ DTT, $10 \mathrm{mM}$ Na3VO4, $10 \mathrm{mM} \mathrm{NaF}$, $1 \mathrm{mM}$ PMSF, $2 \mu \mathrm{g} / \mathrm{ml}$ Pepstain, $2 \mu \mathrm{g} / \mathrm{ml}$ Leupeptin, $2 \mu \mathrm{g} / \mathrm{ml}$ Aprotintin, 10\% (v/v) NP-40, $10 \mathrm{mM} \beta$-Glycerophosphate] after $14,000 \mathrm{rpm}$ centrifuge for $20 \mathrm{~min}$ at $4^{\circ} \mathrm{C}$. Protein was quantified by the Bradford method using bovine serum albumin as the standard (Bradford, 1976). For ELISA analysis, $2 \mu \mathrm{g}$ total proteins were coated in the 96-well plate, and the polyclone antidoby against wheat CaM (generous gift from Prof. Daye Sun in Hebei Normal University) and HRP-labeled goat anti-rabbit IgG antibody (Bioworld Tchnology Inc., St. Louis Park, USA) were used to determine the level of CaM. The results were normalized to the CaM protein level of untreated samples. For Western blot analysis, total proteins were separated on $12 \%$ SDS-polyacrylamide gel, transferred to PVDF film, hybridized with polyclonal antibody against wheat $\mathrm{CaM}$, and detected the accumulation of CaM by HRP-labeled goat anti-rabbit IgG antibody (Bioworld Tchnology
Inc., St. Louis Park, USA). The images were detected by Biodlight ECL Chemiluminescent HRP Kit (Bioworld Technology Co. Ltd, St. Louis Park, USA) and scanned by BIO-RAD ChemiDoc TM MP Imaging System (Bio-Rad Laboratories, Inc. USA). Actin was used as the internal quantification control by using plant actin mAb (Bioworld Tchnology Inc., St. Louis Park, USA).

\section{QUANTITATIVE REAL-TIME PCR (qRT-PCR)}

Seventeen-day-old seedlings were cultured in Hoagland medium with or without $1 \mu \mathrm{M} 3$ OC6-HSL. Roots of the treated plants were harvested at $0,1,2,3,6,12$, and $24 \mathrm{~h}$ after 3OC6-HSL treatment and total RNA was extracted from the treated and untreated roots using the RNAiso Plus reagent (TaKaRa, Dalian, China) according to the manufacturer's instructions. The cDNA was synthesized using the PrimeScript ${ }^{\circledR}$ RT Reagent Kit with gDNA Eraser (TaKaRa, Dalian, China) according to the manufacturer's instructions. For the relative quantification of gene expression, the comparative $\mathrm{C}_{T}$ method (Livak and Schmittgen, 2001) was used with the 7500 Real Time PCR System (Applied Biosystems, Foster City, CA, USA). For qRT-PCR, received cDNA was diluted 15 times in diethylpyrocarbonate-treated water. PCR amplification was done in a total volume of $20 \mu \mathrm{l}$ containing $5 \mu \mathrm{l}$ of diluted cDNA, $0.4 \mu \mathrm{l}$ of each primer $(10 \mu \mathrm{M})$, and $10 \mu \mathrm{l}$ of SYBR Premix Ex Taq (TaKaRa, Shiga, Japan). The following qRT-PCR thermal cycling program was employed: $10 \mathrm{~s}$ at $95^{\circ} \mathrm{C}$ and 40 cycles for $5 \mathrm{~s}$ at $95^{\circ} \mathrm{C}$ and $31 \mathrm{~s}$ at $60^{\circ} \mathrm{C}$. The amount of target was normalized to the endogenous reference gene Actin 2. Values were normalized to the $0 \mathrm{~h}$ time point. For technical control, each qRT-PCR experiment was repeated four times on the same 96-well plate. Each data point represents the average of three independent experiments. A 1.5-fold increase (ratio $>$ 1.5 ) or 1.5 -fold decrease (ratio $<0.8$ ) in expression in the treated plants compared with the untreated plants was considered as upregulation or down-regulation related to 3OC6-HSL response. The specific primers for qRT-PCR are shown in Supplementary Table 1.

\section{IDENTIFICATION OF CaM NULL MUTANTS}

The leaves of one-month-old wild type (Columbia, Col-0) and CaM mutants (cam1-cam9) seedlings cultured in vermiculite were harvested respectively and total RNA was extracted using the RNAiso Plus reagent (TaKaRa, Dalian, China) according to the manufacturer's instructions. The cDNA was synthesized using the PrimeScript ${ }^{\circledR}$ RT Reagent Kit with gDNA Eraser (TaKaRa, Dalian, China) according to the manufacturer's instructions. For RT-PCR, amplification was done in a total volume of $20 \mu \mathrm{l}$ containing $1 \mu \mathrm{l}$ of received cDNA, $1 \mu \mathrm{l}$ of each primer $(10 \mu \mathrm{M})$, $2 \mu \mathrm{l}$ of $10 \times$ PCR buffer, $2 \mu \mathrm{l}$ of $\mathrm{dNTP}(2.5 \mathrm{mM}$ each), $0.2 \mu \mathrm{l}$ of rTaq DNA Polymerase ( 5 units/ $\mu$ l, TaKaRa, Shiga, Japan) and $12.8 \mu \mathrm{l}$ of sterilized distilled water. The following RT-PCR thermal cycling program was employed: initial denaturation for $5 \mathrm{~min}$ at $94^{\circ} \mathrm{C}, 30$ cycles for $40 \mathrm{~s}$ at $94^{\circ} \mathrm{C}, 50 \mathrm{~s}$ at $52^{\circ} \mathrm{C}$ and $1 \mathrm{~min}$ at $72^{\circ} \mathrm{C}$, and then extension for $10 \mathrm{~min}$ at $72^{\circ} \mathrm{C}$. Actin 2 was used as the endogenous reference gene. The primer pairs were designed at $5^{\prime}$-UTR and 3'-UTR respectively for containing ORF sequence of each CaM genes and avoiding homologos mismatches between the nine CaM genes (Supplementary Table 2). 


\section{ANALYSIS OF PRIMARY ROOT GROWTH}

The seeds of wild type (Columbia, Col-0) and mutants Atcam19 (cam1-cam9) germinated at MS agar plate vertically. After 3 days, seedlings with similar root length were transferred to $1 / 2$ MS agar plates containing $1 \mu \mathrm{M}$ 3OC6-HSL or $50 \mu \mathrm{M}$ C10HSL or $50 \mu \mathrm{M}$ C12-HSL. Because of the space limitation in one plate, the seedlings of WT and each three mutants were grown side by side vertically in one plate with the same growth condition as described above. The equivalent $\mathrm{dH}_{2} \mathrm{O}$-treated plants and ethanol-treated plants were taken as the solvent control. Primary root length was assessed with a ruler. In addition, the fresh weight of seedlings were assessed with an electronic balance (accuracy of $10,000 \mathrm{~g}$ ) after 7 days. Each experiment included at least 30 seedlings for each genotype and treatment. Data shown are the average of four independent experiments.

For dissecting the root elongation, the length of root meristem zone and root elongation zone were measured on the 7-daysold seedlings fixed in ethanol: acetic acid (3:1) and mounted in choral hydrate. Mocroscopy was performed on a Leica DM4000 B (CMS GmbH, Wetzlar, Germany) equipped with a Leica DFC 420C camera. Root meristem zone length was assessed as the distance between the quiescent center and the first elongating cell with a vacuole. The length of elongation zone was measured as the distance from the first elongating cell to the first cell with a root hair. The number of the cortical cells in root meristem and elongation zone was obtained by counting the cortical cells under the high-resolution images of the root tips using Image J software (http://rsb.info.nih.gov/ij/). The length of cortical cells in the root meristem or elongation zone was calculated by dividing the root meristem or elongation zone length by the number of the cortical cells in root meristem or elongation zone. At least 20 seedling were processed, and at least three independent experiments were conducted, giving the similar statistically significant results.

\section{STATISTICAL ANALYSIS}

For all experiments, the overall data were statistically analyzed in the DPS v7.05 program. Univariate and multivariate analyses with a Duncan's new multiple range method were used for testing different root growth responses of different ecotype, wild-type, and CaM mutant lines to 3OC6-HSL or to CaM antagonists.

\section{RESULTS}

\section{CaM ANTAGONISTS BLOCK THE IMPACT OF 30C6-HSL ON PRIMARY ROOT LENGTH}

A previous study showed that 3OC6-HSL promotes the primary root elongation of wild-type Arabidopsis (Jin et al., 2012; Liu et al., 2012). Root growth is controlled by the cell division in meristem zone and the cell expansion in elongation zone. In order to dissect the promoting effect of 3OC6-HSL on primary root elongation, we measured the length of meristem and elongation zones in primary roots 7 days after application of 3OC6-HSL to Arabidopsis root systems. The results revealed that the primary roots of plants treated with 3OC6-HSL had both longer meristem and elongation zones than those of solvent-treated wild type plants (Figures 1A,D). The difference in the length of elongation zone $(30.2 \%)$ was much more pronounced than the difference in the length of meristem zone $(13.6 \%)$. To further pinpoint the process whereby 3OC6-HSL functions, we counted the number and calculated the length of cortical cells in the meristem and elongation zone. We found that treatment with 3OC6-HSL caused a $30 \%$ increase in the number of cortical cell in the meristem zone compared to the solvent-treated roots while no significant increase in the length of cortical cells in the meristem zone was observed after 3OC6-HSL treatment, indicating that the increase in meristem size is mainly due to the increased number of cortical cells in root meristem (Figures 1B,C). On the other side, analysis for root elongation zone demonstrated that the elongated root elongation zone induced by 3OC6-HSL contained similar number of cortical cells but longer cells than the control, suggesting an increase in cell expansion (Figures 1E,F). Collectively, these results suggest that 3OC6-HSL promotes primary root growth via changes in cell division and elongation.

Previously we demonstrated that $\mathrm{Ca}^{2+}$ signal is involved in AHL signaling in plant cells (Song et al., 2011). To further analyze the role of CaM in AHL-mediated primary root growth, the effects of different concentrations of CaM antagonists, such as trifluoperazine (TFP) and N-(6-aminohexyl)-5chloro-1- naphthalene-sulphonamide (W-7), on the length of primary roots was first investigated. It was found that the growth of primary roots in the plants only treated with higher concentration W-7 (Figure 2A) or TFP (Figure 2B) was significantly reduced; however, the length of primary roots did not significantly change in the plants treated with $0-50 \mu \mathrm{M}$ concentration of W-7 (Figure 2A) or with $0-1 \mu \mathrm{M}$ concentration of TFP (Figure 2B). W-5 is the dechlorinated analog of $\mathrm{W}-7$ and is often used as control compound for understanding the specificity of $\mathrm{W}-7$. The result shows that no deleterious effect on root elongation was observed for $\mathrm{W}-5$ at the tested concentration (Figure 2A). Therefore, $50 \mu \mathrm{M}$ for $\mathrm{W}-7$ and $1 \mu \mathrm{M}$ for TFP have been considered as a threshold concentration and chosen for subsequent experiments.

Subsequently, we investigated the effect of 3OC6-HSL on root elongation with or without antagonists. Three-day-old seedlings were transferred to $1 / 2 \mathrm{MS}$ medium plates containing $1 \mu \mathrm{M}$ 3OC6-HSL and $50 \mu \mathrm{M} \mathrm{W}-7$ or $1 \mu \mathrm{M}$ TFP and cultivated for additional 7 days. The plates containing $50 \mu \mathrm{M} \mathrm{W}-5$ were taken as control for W-7 treatment. The results showed that the 3OC6HSL-stimulated primary root growth was completely suppressed by addition of $50 \mu \mathrm{M} \mathrm{W}-7$ while $50 \mu \mathrm{M}$ W-5 did not affect the effect of 3OC6-HSL on primary root elongation, indicating that the effect of W-7 was attributable to CaM inhibition (Figure 3). Likewise, $1 \mu \mathrm{M}$ TFP blocked the increase of primary root length in response to 3OC6-HSL as well (Figure 3). These data suggested that CaM has an important role in AHL-stimulated primary root elongation.

\section{TREATMENT WITH 30C6-HSL PROMOTES THE ACCUMULATION OF THE CaM PROTEIN}

Pharmacological analysis implicates that $\mathrm{CaM}$ is required for 3OC6-HSL-mediated primary root elongation (Figure 3). Whether the level of CaM in plant cells is influenced by treatment with 3OC6-HSL has not been resolved. To address this point, we examined the level of CaM protein in Arabidopsis roots reacting to 3OC6-HSL. Total protein was extracted from Arabidopsis 

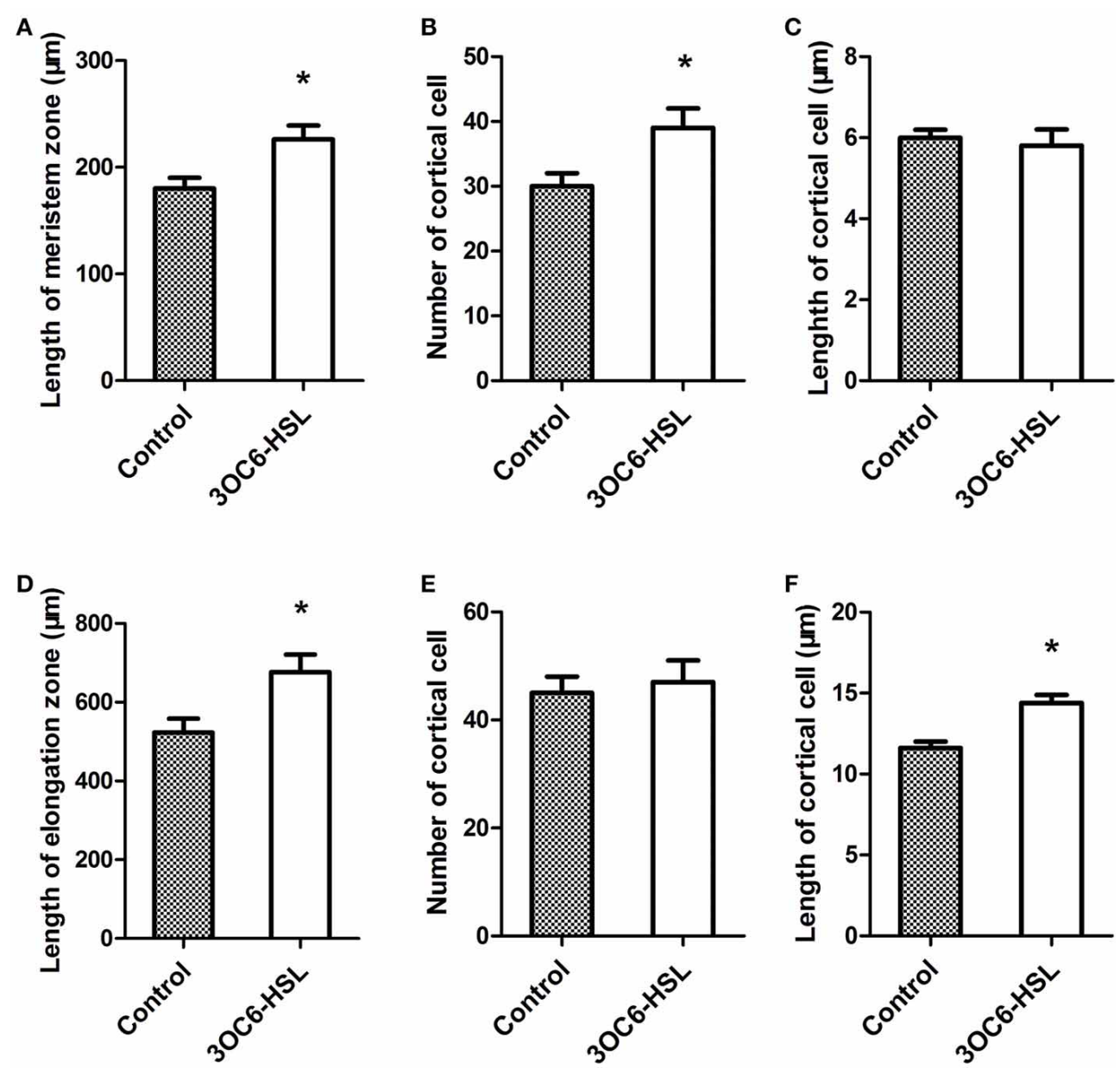

FIGURE 1 | Effects of 30c6-HSL on Arabidopsis root meristem zone and root elongation zone. The length of the root meristem zone (A), the number of cortical cells in the meristem zone (B), the length of the root elongation zone (D) and the number of the cortical cells in elongation zone (E) were measured on the wild type seedlings grown on vertically oriented plates containing with or without $1 \mu \mathrm{M} 30 \mathrm{C} 6-\mathrm{HSL}$ after 7 days of cultivation. The length of cortical cell in the root meristem zone $\mathbf{( C )}$ and in the root elongation zone (F) were calculated by dividing the root meristem or elongation zone length by the number of the cortical cells in the root meristem or elongation zone. Data shown are the average of three independent experiments giving the similar statistically siginificant results. Each experiment included at least 20 seedlings. Entries with $p$-values $<0.05$ shown with asterisk. roots exposed to $1 \mu \mathrm{M} 3$ OC6-HSL at different time points and the overall concentration of CaM protein was determined by western blot and ELISA using specific polyclonal antibody against CaM. Western analysis showed that the concentration of $\mathrm{CaM}$ protein in roots increased after treatment with $1 \mu \mathrm{M}$ 3OC6-HSL and reached the maximum at $6 \mathrm{~h}$ post treatment (Figure $4 \mathrm{~A}$ ). Similarly, ELISA result indicated that treatment with $1 \mu \mathrm{M} 30 \mathrm{OC}-$ HSL promoted the accumulation of CaM protein and the CaM concentration reached a maximum 2-fold increase after $6 \mathrm{~h}$ of treatment with 3OC6-HSL (Figure 4B). These results provide the evidence for a positive regulation of 3OC6-HSL on CaM protein level.

\section{C6-HSL INDUCES THE EXPRESSION OF ALL NINE CaM ISOFORM GENES IN ARABIDOPSIS}

The results described above demonstrated that 3OC6-HSL increased the CaM protein accumulation, however the response of CaM genes to 3OC6-HSL treatment remains unknown.
Therefore, we next investigated the expression profiles of CaM genes after exposure to 3OC6-HSL using qRT-PCR. The Arabidopsis genome contains nine CaM genes encoding CaM protein isoforms (Zielinski, 2002). Since a high nucleic acid sequence conservation exists among nine AtCaM genes, the primers for each AtCaM gene were generally chosen from the $3^{\prime}$ untranslated regions of individual AtCaM genes in order to ensure the discrimination between mRNA of genes belonging to highly conserved gene family. Total RNA was isolated from Arabidopsis roots treated with $1 \mu \mathrm{M}$ 3OC6-HSL and used to perform the real-time RT-PCR. The expressions of all nine AtCaM genes were up-regulated significantly by 3OC6-HSL although the extent of induction differed from different CaM isoform genes (Figure 5). Compared to the untreated control, a more than 4-fold increase in transcript of AtCaM1, AtCaM3, AtCaM6, and AtCaM8 was observed after treatment with 3OC6-HSL. The mRNA levels of AtCaM4, AtCaM5, AtCaM7, and AtCaM9 genes were increased up to 3 -fold by 3OC6-HSL while only 1.7 -fold 


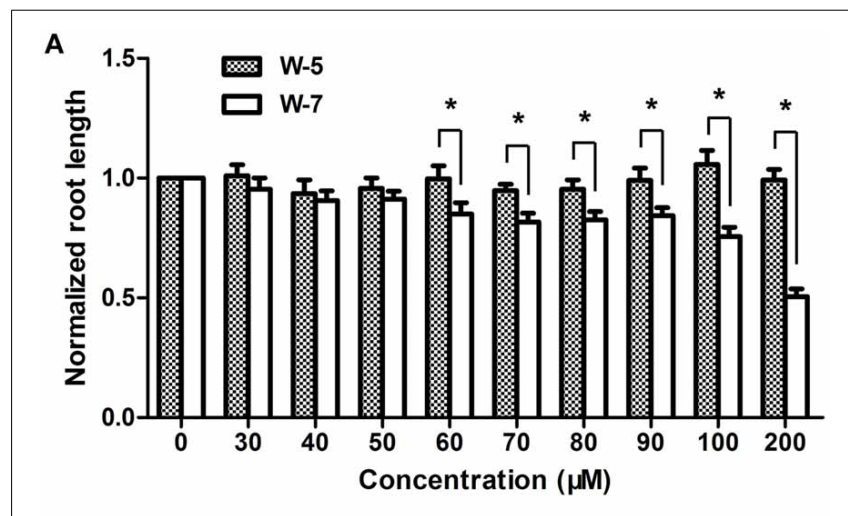

B

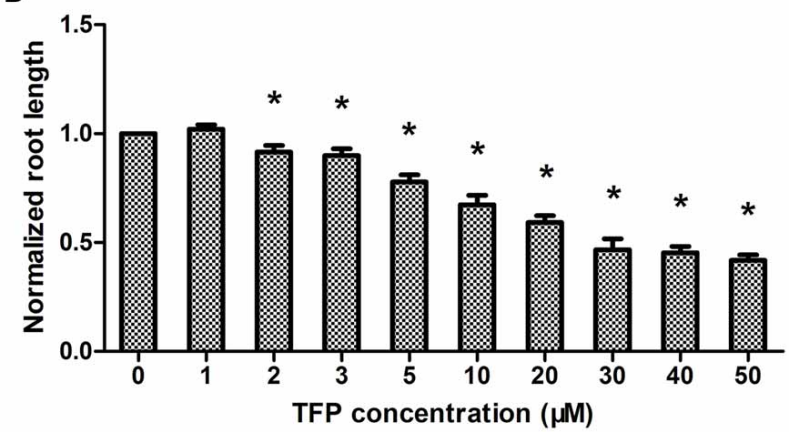

FIGURE 2 | Effects of CaM antagonist W-7 and TFP at different concentration on primary root elongation. Wild-type plants were grown on vertically oriented plates containing indicated concentration of W-7, W-5 (no-activity analog of W-7) or TFP and the primary root length was measured after 7 days of cultivation. (A) Plot of a dose-response evaluation of W-7 and W-5 (30-200 $\mu \mathrm{M})$ on primary root length. (B) Plot of effects of indicated concentration of TFP $(1-50 \mu \mathrm{M})$ on primary root length. The results were normalized to the root lengths of untreated samples. Data shown are the average of three independent experiments. Each experiment included at least 30 seedlings. Entries with $p$-values $<0.05$ shown with asterisk.

increase was observed in the expression of AtCaM2 in response to 3OC6-HSL treatment (Figure 5). In summary, these data indicated that 3OC6-HSL induced the expression of all nine AtCaM genes with variable degree.

\section{MUTATION OF INDIVIDUAL CaM ISOFORM GENES ABOLISH THE PROMOTION OF PRIMARY ROOT LENGTH BY 30C6-HSL}

The available pharmacological and molecular evidence showed that CaM might be involved in primary root elongation regulated by bacterial AHL, but direct genetic evidence for the participation of CaM is still missing. To solve this question and pursue the specificity of different AtCaM isoform in participation in AHL signaling in plant cells, we compared the primary root elongation in response to 3OC6-HSL between wild-type and the T-DNA insertional mutant lines of individual AtCaM gene. All mutants for all nine AtCaM genes are confirmed to be homozigous lines by antibiotic resistance screening and RTPCR (Figure 6D) and exhibit no observed phenotypic differences compared with wild-type plants under normal growth conditions (Figure 6A). As shown in Figure 6, the observed increased root elongation upon 3OC6-HSL exposure in wild-type plant was

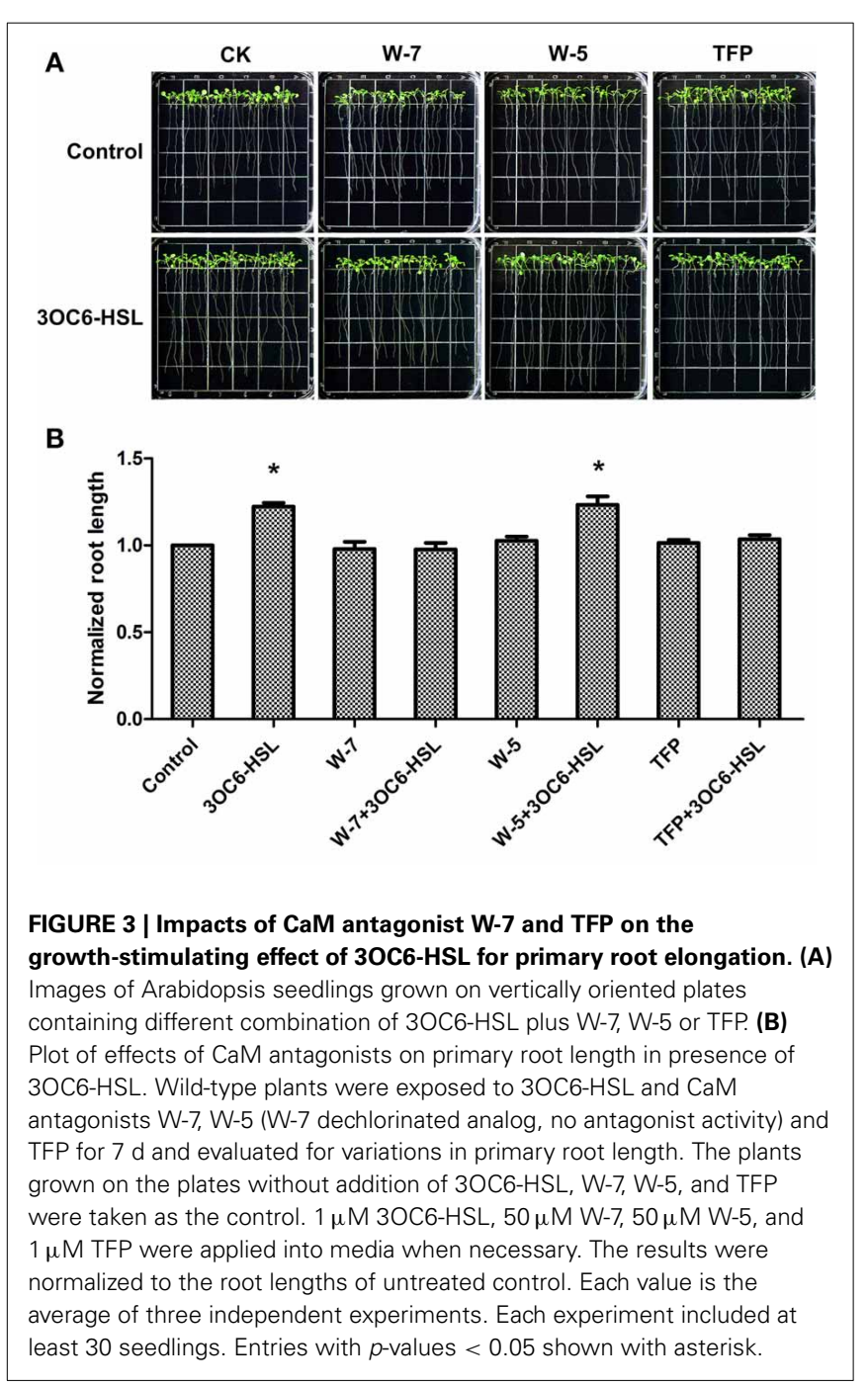

impaired in all mutation lines of nine AtCaM genes. The length of primary roots in cam1, cam2, cam4, cam5, cam6, cam7, and cam 9 after treatment with 30C6-HSL was similar to that of untreated plants of respective mutants (Figures 6A,B). The primary root in cam3 and cam 8 after contact to 3OC6-HSL exhibited even slightly shorter than that of untreated respective mutants, however no significant difference was found between treatment and untreatment with 3OC6-HSL after statistical analysis (Figure 6B). Additionaly, we measured the effects of 3OC6-HSL on the fresh weight of seedlings of wild-type and the individual AtCaM mutants. An obvious increase in the fresh weight of wild type seedlings was observed after treatment with 3OC6-HSL, whereas the fresh weight of seedlings of all nine AtCaM mutants was similar between treated and untreated plants (Figure 6C). Although the conclusion for role of AtCaM in AHL signaling at genetic level needs to be reinforced by complementary and over-expression analysis, our data provide preliminary evidence that all nine AtCaM genes might be involved in plant response to 3OC6-HSL with respect to primary root elongation.

It has been reported that short-side chain AHLs such as C6HSL and 3OC6-HSL promoted primary root elongation (von Rad 
et al., 2008; Jin et al., 2012; Liu et al., 2012) while long-side chain AHLs (10-16 carbons) such as C10-HSL and C12-HSL inhibited primary root growth but promoted the formation of lateral root and root hair (Ortiz-Castro et al., 2008, 2011). To investigate if the inhibitory effects of C10-HSL and C12-HSL on primary root elongation, we compared the primary root length between wild-type and the T-DNA insertional mutants of nine AtCaM genes after exposure to C10-HSL and C12-HSL. The results indicated that while C10-HSL or C12-HSL inhibited the primary root growth but promoted the lateral root and root hair development of wild type plants at concentration of $50 \mu \mathrm{M}$, the responses of

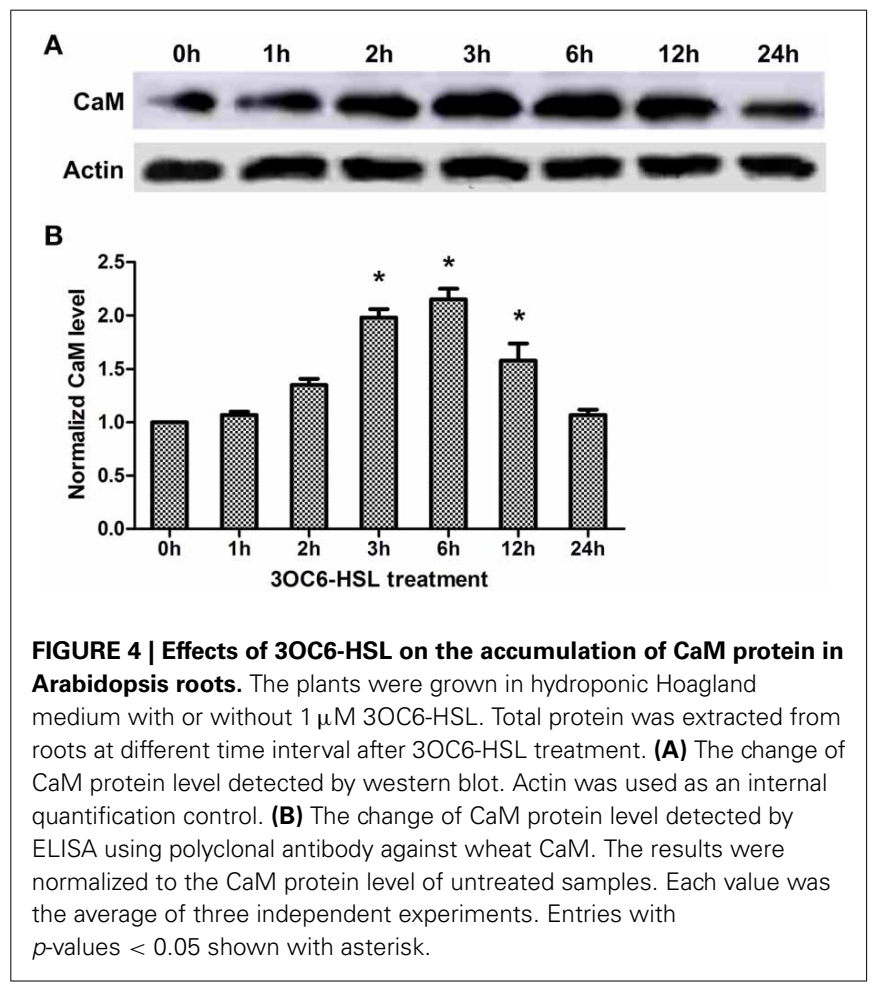

the mutants of nine AtCaM genes to C10-HSL or C12-HSL were similar as that of wild type plants with respect to the root architecture (Figure 7). These data suggested that AtCaMs might not participated in the regulation of root growth and development by the long-chain AHLs.

\section{DISCUSSION}

As one of the most conserved proteins, CaM is thought to be involved in fundamental cellular processes in both animals and plants. In this study, we provide the pharmacological and molecular genetic evidence for involvement of CaM in plant response to bacterial QS signal, 3OC6-HSL, with respect to primary root elongation. To the best of our knowledge, the connection between CaM and 3OC6-HSL signaling in plant cells has not been reported before.

Plant and bacteria have co-existed for millions of years on the earth and a complex networks consisting of different signaling molecules has been evolved. Accumulating evidence suggest that the mechanisms of plant resistance to pathogens or a plants' responding to beneficial microbes share some commonalities. On the other hand, bacterial pathogens and symbionts depend substantially on QS to colonize and infect their host plants. AHLs are the most common QS signals among Gram-negative bacteria. Like microbial-associated molecular patterns (MAMPs), AHLs might be the indicative for plants that pathogens are in the surroundings to gather themselves for attack or that mutualistes are about to interact with plant roots. Accordingly, Hartmann and coworkers suggested that AHLs are important modulators for interaction between plant and bacteria (Hartmann et al., 2014). However, the early events in the perception and transduction of AHLs in plant cells remain unclear. Recently, we found that several bacterial AHLs can elicit changes in the levels of intracellular $\mathrm{Ca}^{2+}$, and $10 \mu \mathrm{M}$ C4-HSL causes a significant, transient increase in the intracellular concentration of free $\mathrm{Ca}^{2+}$ in Arabidopsis root cells (Song et al., 2011). As a mediator protein of $\mathrm{Ca}^{2+}$ signal, $\mathrm{CaM}$ is activated by binding $\mathrm{Ca}^{2+}$, inducing a cascade of regulatory events. However, whether CaM participate the

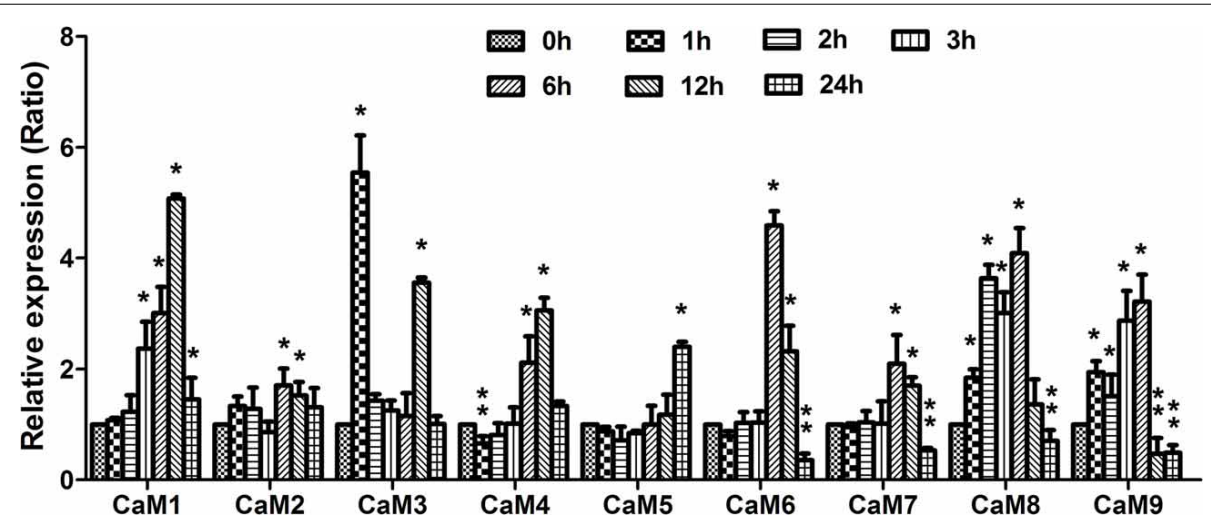

FIGURE 5 | Effects of 30C6-HSL on the expression of CaM genes in Arabidopsis roots. The plants were grown in hydroponic Hoagland medium with or without $1 \mu \mathrm{M} 30 \mathrm{C} 6-\mathrm{HSL}$. Total RNA was extracted from roots at different time interval after 30C6-HSL treatment and analyzed by quantitative RT-PCR with specific primers for individual AtCaM gene. Values were normalized to the $0 \mathrm{~h}$ time point. Data represent the mean from three independent biological replications. Entries with $p$-values $<0.05$ shown with asterisk. Relative expression of genes (ratio) $>1.5$ was considered as up-regulation (single asterisk) and ratio $<0.8$ was considered as down-regulation (double asterisk). 


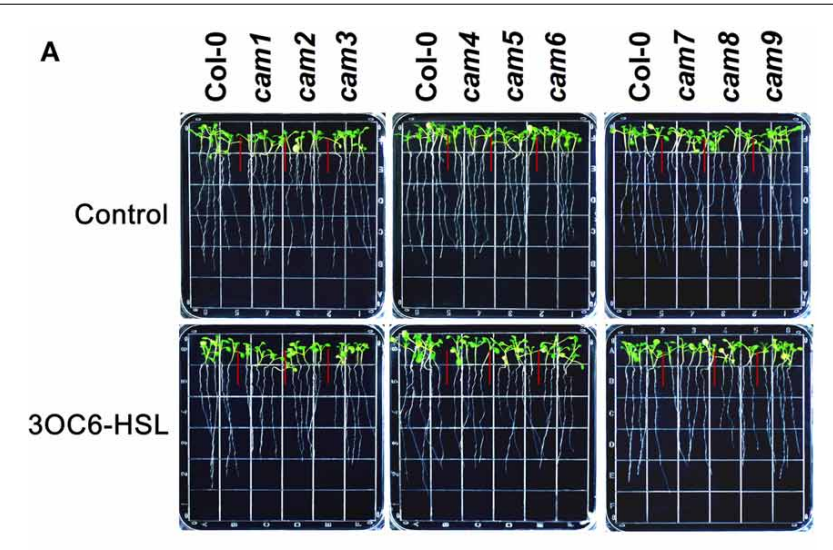

B

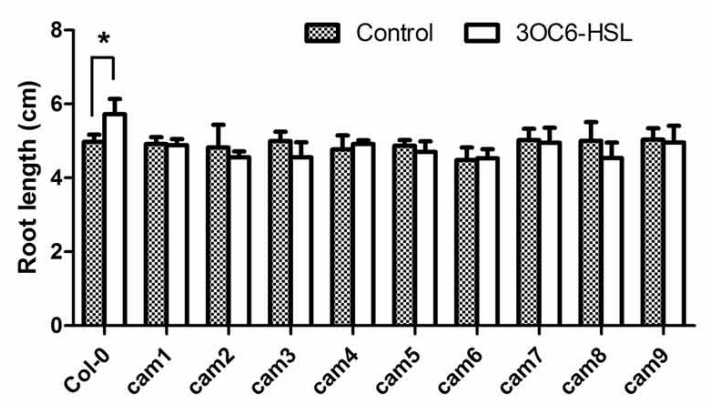

C

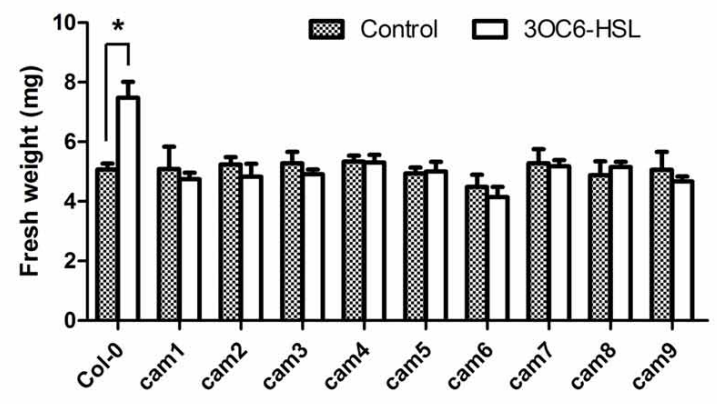

D

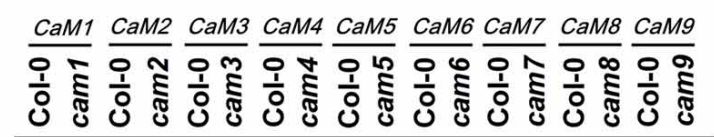

CaM

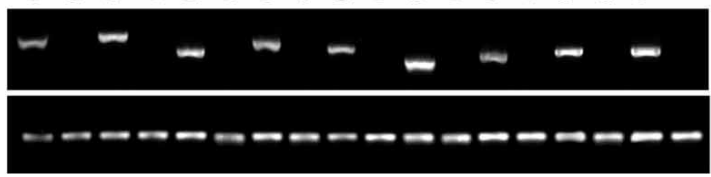

FIGURE 6 | The stimulating effect of 30C6-HSL on primary root elongation is diminished in loss-of-function mutants of individual AtCaM genes. (A) Images of Arabidopsis wild-type plants and CaM functional-deficiency mutants cam1, cam2, cam3, cam4, cam5, cam6, cam7, cam8, and cam9 grown side by side on vertically oriented plates containing with or without $1 \mu \mathrm{M} 30 \mathrm{OC} 6-\mathrm{HSL}$ after 7 days of cultivation. (B) Plot of effect of 30C6-HSL on primary root length in wild-type seedlings and cam1-cam9 mutant seedlings. (C) Plot of effect of 30C6-HSL on fresh weight in wild-type seedlings and cam1-cam9 mutant seedlings. Each experiment included at least 30 seedlings for each genotype and treatment. Data shown are the average of four independent experiments. Entries with $p$-values $<0.05$ shown with asterisk. (D) Identification of CaM null mutants by RT-PCR. Total RNA was extracted from the leaves of one-month-old

(Continued)

\section{FIGURE 6 | Continued}

wild type (Columbia, Col-0) and CaM mutants (cam1-cam9) seedlings and RT-PCR were done to amplify CaM1, CaM2, CaM3, CaM4, CaM5, CaM6, CaM7, CaM8, and CaM9 genes both from wild type RNA and from corresponding CaM mutant RNA. Actin was used as the endogenous reference gene.

downstream cascade of $\mathrm{Ca}^{2+}$ signal triggered by bacterial AHLs remain unknown. Pharmocological assay showed that application of CaM antagonist TFP or W-7 into 3OC6-HSL-treated roots of Arabidopsis abolished the stimulatory effect of 3OC6-HSL on primary root elongation, while $\mathrm{W}-5$, an inactive structural analog of W-7, did not affect the effect of 3OC6-HSL (Figure 3). Control experiments demonstrated that these compounds in the concentration used in this study did not affect the root elongation under normal conditions (Figures 2, 3), indicating that the disappearance of 3OC6-HSL-promoted primary root elongation in presence of TFP or W-7 was due to the inhibited activity of $\mathrm{CaM}$. Then we analyzed the accumulation of CaM protein in plant after treatment with 3OC6-HSL by western blot and ELISA with antibody against $\mathrm{CaM}$ protein. It was found that accumulation of the overall CaM protein in Arabidopsis roots increased in response to 3OC6-HSL and reached its maximum $6 \mathrm{~h}$ after treatment (Figure 4). Thus, the data in this study suggested the involvement of CaM in response of plant to 3OC6-HSL and the role of CaM in 3OC6-HSL-mediated root elongation.

In plant cells, the CaM gene family contains variable members that share a high level of nucleic acid and amino acid sequence identity, and different type of CaM isoforms might has distinct physiological roles. Potato plants have eight CaM genes encoding at least two distinct CaM isoforms, among which the PCM1 gene was up-regulated upon touch and PCM6 during tuberization (Takezawa et al., 1995). Among the five divergent soybean CaM genes, $S C a M-4$ and $S C a M-5$ were transcriptionally activated by phytopathogenic bacterial infection or fungal elicitor application, indicating their involvement in defense against pathogen attack (Lee et al., 1995). Yamakawa et al. (2001) isolated 13 CaM genes from tobacco genome and found that levels of individual CaM genes are differentially regulated both transcriptionally and post-transcriptionally when tobacco are exposed to stresses such as pathogen-induced hypersensitive cell death and wounding. The Arabidopsis genome has nine genetic loci encoding CaM protein isoforms. To determine the role of specific AtCaM gene in response of plant to bacterial 3OC6-HSL, the level of transcription for the nine $\mathrm{CaM}$ genes in root of wild-type seedling grown on medium with and without 3OC6-HSL was measured using specific primers. We found that the expression of all AtCaM genes were up-regulated after treatment with 3OC6-HSL, although the level of gene expression was variable between different $\mathrm{AtCaM}$ members (Figure 5). These data indicated that all these AtCaM isoform genes are 3OC6-HSL -inducible. On the other hand, single AtCaM gene knockout did not exhibit any phenotype difference including primary root growth as compared with the wild-type plants under normal growth conditions (data not shown). These observations together with the data of transcription analysis for nine AtCaM genes after 3OC6-HSL treatment 

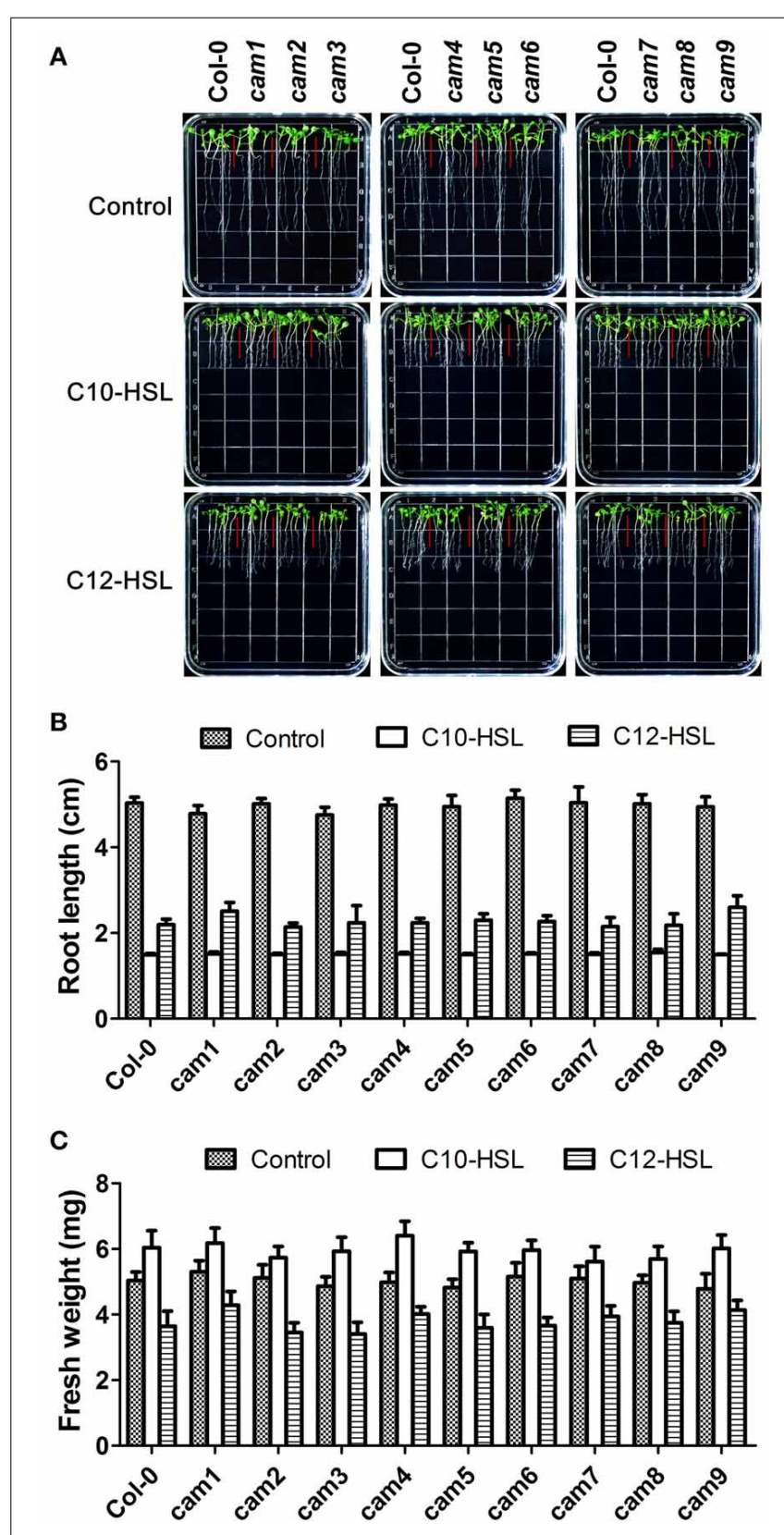

FIGURE 7 | Effects of C10-HSL and C12-HSL on seedling growth in Arabidopsis wild-type plants and CaM functional-deficiency mutants. (A) Images of Arabidopsis wild-type plants and CaM functional-deficiency mutants cam1, cam2, cam3, cam4, cam5, cam6, cam7, cam8, and cam9 grown side by side on vertically oriented plates containing with or without $50 \mu \mathrm{M}$ C10-HSL or $50 \mu \mathrm{M}$ C12-HSL after 7 days of cultivation. (B) Plot of effect of C10-HSL and C12-HSL on primary root length in wild-type seedlings and cam1-cam9 mutant seedlings. (C) Plot of effect of C10-HSL and $\mathrm{C} 12$-HSL on fresh weight in wild-type seedlings and cam1-cam9 mutant seedlings. Ethanol-treated plants were taken as the solvent control. Each experiment included at least 30 seedlings for each genotype and treatment. Data shown are the average of four independent experiments.

gave the hints for the existence of functional redundancy between different AtCaM members for plant growth.

However, mutation of any single AtCaM gene abolished the stimulatory effect of 3OC6-HSL on primary root elongation and the fresh weight (Figure 6). The presence of other AtCaM gene in one of AtCaM T-DNA insertion mutant seemed not to rescue the increased primary root elongation caused by treatment with 3OC6-HSL. It should be noted that more evidence need to be obtained from the complementary or over-expressing lines of individual AtCaM gene. On the other hand, there exist a possibility that some other genes are perhaps required and play additive or complimentary functions. Nevertheless, the molecular and genetic evidence showed the participation of AtCaM genes in the response of Arabidopsis to bacterial QS signal 3OC6-HSL. At moment, we could not figure out the specificity of individual AtCaM gene in participating the AHL-mediated primary root growth. Liu et al. (2005) found that the expression of nine AtCaM genes (AtCaM 1-9) was differentially regulated by heatshock (HS) at $37^{\circ} \mathrm{C}$. The expression of AtCaM3 and AtCaM7 genes increased, while the expression of AtCaM2, AtCaM5, and AtCaM6 decreased during HS. The levels of AtCaM1, AtCaM4, and AtCaM8 mRNA showed no change during HS. Furthermore, molecular and genetic evidence suggest that endogenous AtCaM3 is a key component in HS signaling in Arabidopsis. On the other hand, AI-Quraan et al. (2010) reported that AtCaM1 and AtCaM5 play important roles in response to $\mathrm{HS}$ at $42^{\circ} \mathrm{C}$. These inconsistent results implicated the complexity of AtCaM participating in the signal transduction of response to the external stimuli.

Previous studies revealed that AHLs exert concentration and acyl-chain length dependent effects on plant primary root growth (Ortiz-Castro et al., 2008, 2011; von Rad et al., 2008; Jin et al., 2012; Liu et al., 2012; Palmer et al., 2014). Generally, AHLs with short-side chain such as C6-HSL and 3OC6-HSL promoted primary root elongation (von Rad et al., 2008; Jin et al., 2012; Liu et al., 2012) while AHLs with long-side chain (10-16 carbons) such as C10-HSL and 3OC12-HSL inhibited primary root length but promoted the formation of laterous root and root hair (OrtizCastro et al., 2008, 2011). In addition, even 3OC6-HSL and C6HSL which exhibit a stimulating effects on primary root growth at concentration below $10 \mu \mathrm{M}$ showed an inhibitory effects on root length when higher concentration were used (Palmer et al., 2014). In the present study, we found that the prolonged primary root caused by 3OC6-HSL with the tested concentration was the consequence of increased cell division in meristic zone and increased cell elongation in elongation zone (Figure 1). These observation implicated that plants might perceive and respond to different types of AHLs in a different manner. In this study, we provided the evidence that CaM activation might be the early event in 3OC6HSL signaling in plant cells. However, the genetic evidence shows that CaM may not participates the inhibition of primary root length caused by application of long-chained AHLs such as C10HSL and C12-HSL (Figure 7). A more thorough understanding of how CaM regulates plant responses to different types of AHL is of great importance. Such investigation is under way.

Our previous work has shown that G-protein-coupled receptor (GPCR) and heterotrimeric G-protein are involved in AHLmediated primary root elongation of Arabidopsis, and GPCRs might be the candidate receptor for AHL in plant cells (Liu et al., 2012). Moreover, a transient elevation in $\left[\mathrm{Ca}^{2+}\right]_{i}$ concentration could be induced by a number of AHL in plants and the $\mathrm{Ca}^{2+}$ influx from the extracellular space into the cells contributed mainly to the increased concentration of cytosolic free $\mathrm{Ca}^{2+}$ 
(Song et al., 2011). Based on our findings herein, we propose a hypothesis that 3OC6-HSL might first be perceived by GPCR and then activate $\mathrm{G} \alpha$. $\mathrm{G} \alpha$ activation is closely followed by an increase in $\mathrm{Ca}^{2+}$ through opening of $\mathrm{Ca}^{2+}$ channels in the plasma membrane. The elevated level of cytoplasmic $\mathrm{Ca}^{2+}$ then directly activates CaM and promotes the expression and accumulation of CaM. Activated CaM triggers the downstream cascades that ultimately lead to the specific cellular reaction. Further studies are needed to identify the downstream target proteins of activated $\mathrm{CaM}$ and to find how CaM activates its target proteins.

\section{AUTHOR CONTRIBUTIONS}

Qian Zhao and Chao Zhang contributed equally to this work and performed the pharmocological analysis and molecular, genetic assay, respectively. Yali Huang, Zhenhua Jia and Haili Li have helped with the acquisition, analysis and interpretation of data for the work. Shuishan Song is responsible for the design of the work.

\section{ACKNOWLEDGMENTS}

We thank Prof. Sujuan Cui for providing CaM mutant seeds of cam2, cam3, and cam4. We also thank Prof. Daye Sun for providing polyclone antidoby against CaM. This work was financially supported by a project from the National Basic Research Programm of China (No. 2015CB150604), the National Natural Science Foundation of China (No. 31270880), and the Key Basic Research Program of Hebei (No. 12960306D).

\section{SUPPLEMENTARY MATERIAL}

The Supplementary Material for this article can be found online at: http://www.frontiersin.org/journal/10.3389/fpls.2014.00807/ abstract

\section{REFERENCES}

AI-Quraan, N. A., Locy, R. D., and Singh, N. K. (2010). Expression of calmodulin gene in wild type and calmodulin mutants of Arabidopsis thaliana under heat stress. Plant Physiol. Biochem. 48, 697-702. doi: 10.1016/j.plaphy.2010.04.011

Bai, X., Todd, C. D., Desikan, R., Yang, Y., and Hu, X. (2012). N-3-oxodecanoylL-homoserine-lactone activates auxin-induced adventitious root formation via hydrogen peroxide- and nitric oxide-dependent cyclic GMP signaling in mung bean. Plant Physiol. 158, 725-736. doi: 10.1104/pp.111.185769

Bassler, B. L. (1999). How bacteria talk to each other: regulation of gene expression by quorum sensing. Curr. Opin. Microbiol. 2, 582-587. doi: 10.1016/S13695274(99)00025-9

Braam, J., and Davis, R. W. (1990). Rain-, wind- and touch-induced expression of calmodulin and calmodulin-related genes in Arabidopsis. Cell 60, 357-364. doi: 10.1016/0092-8674(90)90587-5

Bradford, M. M. (1976). A rapid and sensitive method for the quantitation of microgram quantities of protwin utilizing the principle of protein-dye binding. Anal. Biochem. 72, 248-254.

Cheval, C., Aldon, D., Galaud, J. P., and Ranty, B. (2013). Calcium/calmodulinmediated regulation of plant immunity. Biochim. Biophys. Acta 1833, 1766-1771. doi: 10.1016/j.bbamcr.2013.01.031

Chin, D., and Means, A. R. (2000). Calmodulin: a prototypical calcium sensor. Trends Cell Biol. 10, 322-328. doi: 10.1016/S0962-8924(00)01800-6

Fuqua, C., Parsek, M. R., and Greenberg, E. P. (2001). Regulation of gene expression by cell-to-cell communication: acyl-himoserine lactone quorum sensing. Annu. Rev. Genet. 35, 439-468. doi: 10.1146/annurev.genet.35.102401.090913

Fuqua, C., and Greenberg, E. P. (2002). Listening in on bacteria: acyl-homoserine lactone signalling. Nat. Rev. Mol. Cell Biol. 3, 685-695. doi: 10.1038/nrm907

Gong, M., Li, Y. J., Dai, X., Tian, M., and Li, Z. G. (1997). Involvement of calcium and calmodulin in the acquisition of heat shock induced thermotolerance in maize seedlings. J. Plant Physiol. 150, 615-621.
Götz, C., Fekete, A., Gebefuegi, I., Forczek, S.T., Fuksová, K., Li, X., et al. (2007) Uptake, degradation and chiral discrimination of $\mathrm{N}$-acyl-D/L-homoserine lactones by barley (Hordeum vulgare) and yam bean (Pachyrhizus erosus) plants. Anal. Bioanal. Chem. 389, 1447-1457. doi: 10.1007/s00216-007-1579-2

Hartmann, A., Rothballer, M., Hense, B. A., and Schröder, P. (2014). Bacterial quorum sensing compounds are important modulators of microbe-plant interactions. Front. Plant Sci. 5:131. doi: 10.3389/fpls.2014.00131

Heo, W. D., Lee, S. H., Kim, M. C., Kim, J. C., Chung, W. S., Chun, H. J., et al. (1999). Involvement of specific calmodulin isoforms in salicylic acidindependent activation of plant disease resistance responses. Proc. Natl. Acad. Sci. U.S.A. 96, 766-771. doi: 10.1073/pnas.96.2.766

Jin, G., Liu, F., Jia, Z., Bian, Z., and Song, S. (2012). Involvement of two G-proteincoupled-receptor candidates, Cand 2 and Cand7, in Arabidopsis root growth mediated by $N$-acyl-homoserine lactones, the bacterial quorum-sensing signals. Biochem. Biophys. Res. Commun. 417, 991-995. doi: 10.1016/j.bbrc.2011.12.066

Knight, M. R., Campbell, A. K., Smith, S. M., and Trewavas, A. J. (1991). Transgenic plant aequorin reports the effects of touch and cold-shock and elicitors on cytoplasmic calcium. Nature 352, 524-526. doi: 10.1038/352524a0

Lee, S. H., Kim, J. C., Lee, M. S., Heo, W. D., Seo, H. Y., Yoon, H. W., et al. (1995). Identification of a novel divergent calmoculin isoform form soybean which has differential ability to activate calmodulin-dependent enzymes. J. Biol. Chem. 270, 21806-21812. doi: 10.1074/jbc.270.37.21806

Liu, F., Bian, Z., Jia, Z., Zhao, Q., and Song, S. (2012). The GCR1 and GPA1 participate in promotion of Arabidopsis primary root elongation induced by $N$-acyl-homoserine lactones, the bacterial quorum-sensing signals. Mol. Plant Microbe Interact. 25, 677-683. doi: 10.1094/MPMI-10-11-0274

Liu, H. T., Li, B., Shang, Z. L., Li, X. Z., Mu, R. L., Sun, D. Y., et al. (2003). Calmodulin is involved in heat shock signal transduction in wheat. Plant Physiol. 132, 1186-1195. doi: 10.1104/pp.102.018564

Liu, H. T., Sun, D. Y., and Zhou, R. G. (2005). $\mathrm{Ca}^{2+}$ and AtCaM3 are involved in the expression of heat shock protein gene in Arabidopsis. Plant Cell Environ. 28, 1276-1284. doi: 10.1111/j.1365-3040.2005.01365.x

Livak, K. J., and Schmittgen, T. D. (2001). Analysis of relative gene expression data using real-time quantitative PCR and the 2(-Delta Delta C $(\mathrm{T})$ ) Method. Methods 25, 402-408. doi: 10.1006/meth.2001.1262

Mathesius, U., Mulders, S., Gao, M., Teplitski, M., Caetano-Anolles, G., Rolfe, B. G., et al. (2003). Extensive and specific responses of a eukaryote to bacterial quorum-sensing signals. Proc. Natl. Acad. Sci. U.S.A. 100, 1444-1449. doi: 10.1073/pnas.262672599

Miao, C., Liu, F., Zhao, Q., Jia, Z., and Song, S. (2012). A proteomic analysis of Arabidopsis thaliana seedling responses to 3-oxo-octanoyl-homoserine lactone, a bacterial quorum-sensing signal. Biochem. Biophys. Res. Commun. 427, 293-298. doi: 10.1016/j.bbrc.2012.09.044

Morquecho-Contreras, A., Méndez-Bravo, A., Pelagio-Flores, R., Raya-González, J., Ortíz-Castro, R., and López-Bucio, J. (2010). Characterization of $d r r 1$, an alkamide-resistant mutant of Arabidopsis, reveals an important role for small lipid amides in lateral root development and plant senescence. Plant Physiol. 152, 1659-1673. doi: 10.1104/pp.109.149989

Miller, M. B., and Bassler, B. L. (2001). Quorum sensing in bacteria. Annu. Rev. Microbiol. 55, 165-199. doi: 10.1146/annurev.micro.55.1.165

Murashige, T., and Skoog, F. (1962). A revised medium for rapid growth and bio assays with tobacco tissue cultures. Physiol. Plant 15, 473-497. doi: 10.111/j.1399-3054.1962.tb08052.x

Ortega, X., Polanco, R., Castañeda, P., and Perez, L. M. (2002). Siganl transduction in lemon seedlings in the hypersensitive response against Alternaria alternata participation of calmodulin, G-protein and protein kinases. Biol. Res. 35, 373-383. doi: 10.4067/S0716-97602002000300012

Ortiz-Castro, R., Martínez-Trujillo, M., and López-Bucio, J. (2008). N-acyl-Lhomoserine lactones: a class of bacterial quorum-sensing signals alter postembryonic root development in Arabidopsis thaliana. Plant Cell Environ. 31, 1497-1509. doi: 10.1111/j.1365-3040.2008.01863.x

Ortiz-Castro, R., Díaz-Pérez, C., Martínez-Trujillo, M., del Río, R. E., CamposGarcía, J., and López-Bucio, J. (2011). Transkingdom signaling based on bac terial cyclodipeptides with auxin activity in plants. Proc. Natl. Acad. Sci. U.S.A. 108, 7253-7258. doi: 10.1073/pnas. 1006740108

Palmer, A. G., Senechal, A. C., Mukherjee, A., Ané, J. M., and Blackwell, H. E. (2014). Plant responses to bacterial $N$-acyl-L-homoserine lactones are dependent on enzymatic degradation to L-homoserine. ACS Chem. Biol. 9, 1834-1845. doi: 10.1021/cb500191a 
Pelagio-Flores, R., Ortiz-Castro, R., and López-Bucio, J. (2013). dhm1, an Arabidopsis mutant with increased sensitivity to alkamides shows tumorous shoot development and enhanced lateral root formation. Plant Mol. Biol. 81, 609-625. doi: 10.1007/s11103-013-0023-6

Quiñones, B., Dulla, G., and Lindow, S. E. (2005). Quorum sensing regulates exopolysaccharide production, motily, and virulence in Pseudomonas syringae. Mol. Plant Microbe Interact. 18, 682-693. doi: 10.1094/MPMI-18-0682

Sander, D., Brownlee, C., and Harper, J. F. (1999). Communication with calcium. Plant Cell 11, 691-706. doi: 10.1105/tpc.11.4.691

Schenk, S. T., Stein, E., Kogel, K. H., and Schikora, A. (2012). Arabidopsis growth and defense are modulated by bacterial quorum sensing molecules. Plant Signal. Behav. 7, 178-181. doi: 10.4161/psb.18789

Schenk, S. T., Hernández-Reyes, C., Samans, B., Stein, E., Neumann, C., Schikora M., et al. (2014). $N$-acyl-homoserine lactone primes plants for cell wall reinforcement and induces resistance to bacterial pathogens via the salicylic acid/oxylipin pathway. Plant Cell 26, 2708-2723. doi: 10.1105/tpc.114.126763

Schikora, A., Schenk, S. T., Stein, E., Molitor, A., Zuccaro, A., and Kogel, K. H. (2011). $N$-acyl-homoserine lactone confers resistance toward biotrophic and hemibiotrophic pathogens via altered activation of AtMPK6. Plant Physiol. 157, 1407-1418. doi: 10.1104/pp.111.180604

Schuhegger, R., Ihring, A., Gantner, S., Bahnweg, G., Knappe, C., Vogg, G., et al. (2006). Induction of systemic resistance in tomato by $N$-acyl-L-homoserine lactone-producing rhizosphere bacteria. Plant Cell Environ. 29, 909-918. doi: 10.1111/j.1365-3040.2005.01471.x

Sieper, T., Forczek, S., Matucha, M., Krämer, P., Hartmann, A., and Schröder, P. (2014). $N$-acyl-homoserine lactone uptake and systemic transport in barley rest upon active parts of the plant. New Phytol. 201, 545-555. doi: 10.1111/nph.12519

Snedden, W. A., and Fromm, H. (2001). Calmodulin as a versatile calcium signal transducer in plants. New Phytol. 151, 35-66. doi: 10.1046/j.14698137.2001.00154.x

Song, S., Jia, Z., Xu, J., Zhang, Z., and Bian, Z. (2011). N-butyrylhomoserine lactone, a bacterial quorum-sensing signaling molecule, induces intracellular calcium elevation in Arabidopsis root cells. Biochem. Biophys. Res. Commun. 414, 355-360. doi: 10.1016/j.bbrc.2011.09.076

Taga, M. E., and Bassler, B. L. (2003). Chemical communication among bacteria. Proc. Natl. Acad. Sci. U.S.A. 100, 14549-14554. doi: 10.1073/pnas.1934514100

Takezawa, D., Liu, Z. H., An, G., and Poovaiah, B. W. (1995). Calmodulin gene family in potato: developmental and touch-induced expression of the mRNA encoding a novel isoform. Plant Mol. Biol. 27, 693-703. doi: 10.1007/BF00020223

van der Luit, A. H., Olivari, C., Haley, A., Knight, M. R., and Trewavas, A. J. (1999). Distinct calcium signaling pathways regulate calmodulin gene expression in tobacco. Plant Physiol. 121, 705-714. doi: 10.1104/pp.121.3.705 von Rad, U., Klein, I., Dobrev, P. I., Kottova, J., Zazimalova, E., and Fekete, A., et al. (2008). Response of Arabidopsis thaliana to $N$-hexanoyl-DL-homoserinelactone, a bacterial quorum sensing molecule produced in the rhizosphere. Planta 229, 73-85. doi: 10.1007/s00425-008-0811-4

Yamakawa, H., Mitsuhara, I., Ito, N., Seo, S., Kamada, H., and Ohashi, Y. (2001). Transcriptionally and post-transcriptionally regulated response of 13 calmodulin genes to tobacco mosaic virus-induced cell death and wounding in tobacco plant. Eur. J. Biochem. 268, 3916-3929. doi: 10.1046/j.1432-1327.2001. 02301.x

Yang, T., Segal, G., Abbo, S., Feldmam, M., and Fromm, H. (1996). Characterization of the calmodulin gene family in wheat: structure, chromosomal location, and evolutional aspects. Mol. Gen. Genet. 252, 684-694. doi: 10.1007/BF021 73974

Zarkani, A. A., Stein, E., Röhrich, C. R., Schikora, M., Evguenieva-Hackenberg, E., Degenkolb, T., et al. (2013). Homoserine lactones influence the reaction of plants to rhizobia. Int. J. Mol. Sci. 14, 17122-17146. doi: 10.3390/ijms1408 17122

Zhang, W., Zhou, R. G., Gao, Y. J., Zheng, S. Z., Xu, P., Zhang, S. G., et al. (2009). Molecular and genetic evidence for the key role of AtCaM3 in heatshock signal transduction in Arabidopsis. Plant Physiol. 149, 1773-1784. doi: 10.1104/pp.108.133744

Zielinski, R. E. (2002). Characterization of three new members of the Arabidopsis thaliana calmodulin gene family: conserved and highly diverged members of the gene family functionally complement a yeast calmodulin null. Planta 214 446-455. doi: 10.1007/s004250100636

Conflict of Interest Statement: The authors declare that the research was conducted in the absence of any commercial or financial relationships that could be construed as a potential conflict of interest.

Received: 29 September 2014; accepted: 26 December 2014; published online: 13 January 2015.

Citation: Zhao Q, Zhang C, Jia Z, Huang Y, Li H and Song S (2015) Involvement of calmodulin in regulation of primary root elongation by $N$-3-oxo-hexanoyl homoserine lactone in Arabidopsis thaliana. Front. Plant Sci. 5:807. doi: 10.3389/fpls.2014.00807 This article was submitted to Plant-Microbe Interaction, a section of the journal Frontiers in Plant Science.

Copyright (c) 2015 Zhao, Zhang, Jia, Huang, Li and Song. This is an open-access article distributed under the terms of the Creative Commons Attribution License (CC BY). The use, distribution or reproduction in other forums is permitted, provided the original author(s) or licensor are credited and that the original publication in this journal is cited, in accordance with accepted academic practice. No use, distribution or reproduction is permitted which does not comply with these terms. 